\title{
AQUISIÇÃO E TITULARIDADE DAS COISAS VAGAS: TRATAMENTO SISTEMÁTICO E O PAPEL INSTITUCIONAL DA ADVOCACIA PÚblica
}

\author{
DANIEL BUCAR ${ }^{1}$ \\ CAIO RIBEIRO PIRES ${ }^{2}$
}

RESUMO: O presente trabalho investiga o tratamento concedido pelo direito brasileiro às coisas vagas, cuja titularidade deixa de pertencer a particular e se transfere ao patrimônio do Município. Inicialmente busca-se expor o fundamento da destinação dos bens vacantes para a municipalidade, além de serem apresentados os distintos regimes sob os quais esta aquisição de propriedade ocorre. Diante deste panorama, constata-se uma estrutura semelhante de arrecadação de bens ou patrimônios, que precede a incorporação ao patrimônio municipal após determinado lapso temporal. Neste sentido, realizam-se também algumas observações referentes ao papel da Advocacia Pública municipal nos momentos de arrecadação e aquisição dos bens. Assim, destaca-se o correto manejo de ferramentas jurídicas, típicas de direito civil, a fim de adquirir bens móveis não titularizados de valor expressivo e questiona-se também a noção, teórica, de titularidade compulsória do Município quando concretizada a vacância. A partir deste recorte propõe-se expediente institucional de análise na aquisição de coisas vagas. Desta forma impede-se o Município de adquirir bens que gerem a atração de um passivo que inutiliza os ganhos originados da entrada de ativo no patrimônio público.

Palavras-Chave: interesse local; função social da propriedade; viabilidade de aquisição; titularidade compulsória.

AbStRACT: This article intends to investigate the brazilian legal treatment for the vague things. They are properties without owner wich are incorporate to the Municipal patrimony. In the beginning the reason for the legal order grant this

\footnotetext{
${ }^{1}$ Doutor pela Universidade do Estado do Rio de Janeiro - UERJ (Brasil). Professor Titular de Direito Civil no IBMEC/RJ. E-mail: bucar@bucarmarano.com.br:. ORCID: 0000-0001-8130-306X (disponível em http://orcid.org/0000-0001-8130-306X).

2 Mestrando em Direito Civil pela Universidade do Estado do Rio de Janeiro-UERJ (Brasil). E-mail: crp@bucarmarano.com.br. ORCID: 0000-0002-0852-3792 (disponível em https://orcid.org/00000002-0852-3792).
} 
estate to the county are shown and the many different regimes for the acquisition of this assets. Is perceived the similar structure of collection and incorporation of goods after certain time lapse, because the owner does not take it back to himself, which serves to the same function. In this way some observations are made concerning to the paper of public law in this task. Attention is drawn to the civil law experience in acquisition of movable property wich have great value and the notion of compulsory ownership is questioned. Based on this theoretical concept one duty to analyze the acquisition of vague things is proposed. This conduct avoids the county to get some goods who manage debts that make unfeasible the entering of assets on the public patrimony.

KEYWORDS: local interest; social function of property; viability of acquisition; compulsory title.

\section{INTRODUÇÃO}

As concepções de direito civil outrora dominantes possibilitaram o esquecimento doutrinário a respeito de certos temas, o que não significa a inexistência de controvérsia sobre tais assuntos. Tampouco pode se afirmar, como razão deste silêncio, a desnecessidade destas disciplinas pela inocorrência de fatos que as reclamem.

No âmbito dos direitos patrimoniais as disposições referentes às coisas vagas ${ }^{3}$ constituem exemplo desta afirmação. Afinal, a concepção individualista e abstrata da propriedade, junto à instituição da família patriarcal, destinada à procriação e à manutenção nobiliárquica, alçavam ao protagonismo, no direito civil, diferentes preocupações.

Onde a propriedade privada definia a relevância jurídica do sujeito de direito ${ }^{4}$ interessava desenvolver as faculdades e poderes do proprietário e não as consequências da falta de titularidade. Esta sistemática normativa sugeria uma improbabilidade de bens, principalmente imóveis, sem proprietário ${ }^{5}$. Nem mesmo havia interesse, ou coerência à ideologia liberal, em determinar a perda de propriedade por aqueles titulares formais que não se utilizavam dos bens. Não só,

\footnotetext{
${ }^{3}$ Faz-se um esclarecimento inicial. Embora se esteja ciente da discussão doutrinária que diferencia "coisas" e "bens "o presente artigo adota as expressões "coisas vagas" e "bens vagos" como sinônimos, posto que a distinção não apresenta maiores implicações no tema apresentado. Sobre a diferenciação e os posicionamentos envolvidos, consultar Pereira (2010, p. 343-347). ${ }^{4}$ Sobre o tema seja permitido remeter a Tepedino (2007, p. 37-53).

${ }^{5}$ Para uma construção deste esquema abstrato, segundo o qual todas as terras ou estariam no patrimônio de algum particular ou do Estado, Dantas (1984, p. 165).
} 
a composição tradicional de família, composta por cônjuge e filhos, faziam a vacância hipótese ainda mais distante.

Contudo, isto não significa dizer que a codificação civil não tratou o assunto. De fato, constata-se a previsão de uma estrutura legislativa que trata do tema, desde o Código Civil de 1916, permanecendo no Código Civil de 2002. No entanto, o debate acerca do sistema ora vigente pouco se desenvolveu.

Quanto às razões para endereçar o bem a determinado ente federativo, o direito privado delega os estudos ao direito administrativo ${ }^{6}$ e constitucional. Tal compartimentalização reflete resquício de antiga concepção fictícia, consubstanciada na estanque divisão entre o direito público e privado, cujos temas limítrofes acabam por não ser tocados por ambas as áreas.

Entretanto, mediante as premissas de Direito Civil Constitucional o tema merece um olhar mais cuidadoso ${ }^{7}$. A incidência de valores constitucionais na unidade do ordenamento jurídico torna ultrapassada a clássica divisão entre os ramos do direito, vez que todos devem justificar-se na Constituição da República (MORAES, 1991, p. 66).

Logo, esta mesma tábua axiológica oferece um sentido para que a propriedade privada que não se encontre sob a titularidade de um particular seja concedida, na atualidade, não só ao Poder Público, mas sim, especificamente, ao Município. Definir a supracitada ratio é essencial, inclusive, a informar o Poder Judiciário, que vem tendo dificuldade no tratamento do tema.

Com efeito, em dificultosa pesquisa empreendida para melhor compreensão do assunto encontraram-se decisões permitindo o depositário doar os bens abandonados $^{8}$, o leiloeiro dispor e destinar o produto de acordo com sua conveniência ${ }^{9}$, cuja faculdade também foi conferida em certa ocasião ao locador

${ }^{6}$ No tocante a destinação dos bens públicos e a relevância da matéria para o Direito Administrativo, ver Pereira (2010, p. 376-377).

${ }^{7}$ Em trabalho enfrentando o tema sob esta perspectiva, ver Lustosa (2012).

${ }^{8}$ Conforme se vê do relatório da Decisão Monocrática proferida no AGRAVO EM RECURSO ESPECIAL № 1.135.113 - SP (2017/0170912-9), de que foi Relator o Min. Moura Ribeiro (30.10.2017): “Finalmente, não comporta alteração a parte da sentença que determinou a doação dos bens móveis abandonados no espaço locado, porquanto durante toda a instrução processual, a parte ré se manteve inerte em relação a tais bens, não sendo justo e razoável exigir da locadora suportar encargos relativos ao depósito dos referidos bens por maior lapso temporal, observando que o MM. Juiz facultou a retirada, em sendo de interesse, removendo-os".

${ }^{9}$ Este foi o teor da notícia encontrada no site do Conselho Nacional de Justiça, acerca da convocação de proprietários de bens judicialmente depositados junto a órgãos judiciais integrantes do Tribunal Regional do Trabalho da 5 $5^{\mathrm{a}}$ Região: “Caso os interessados não apareçam ou não preencham as condições para a retirada dos bens no prazo estabelecido, o TRT5 vai considerar abandono imediato dos bens e autorizar ao leiloeiro dar a destinação que julgar cabível aos lotes abandonados, inclusive alienação para reembolso das despesas de remoção e armazenagem". 
quanto a coisas deixadas pelo inquilino no imóvel alugado ${ }^{10}$. Poucas decisões observavam a normativa vigente e chamavam a municipalidade para se manifestar no feito.

Contudo, se a redução do tamanho das famílias e o acúmulo de riqueza ${ }^{11}$ apontam para uma maior propensão de heranças vagas, de outro lado, a obsolescência programada, o ritmo acelerado econômico e os altos números da violência urbana no Brasil indicam uma maior possibilidade de bens vagos. Dito de outra forma, a própria realidade social determina um estudo da disciplina das coisas e patrimônios vagos.

Diante disto, o presente estudo pretende trazer algumas bases para reconstrução deste debate e traçar, conforme a normativa existente, o papel da Advocacia Pública na arrecadação e incorporação dos bens vagos ao patrimônio do Município. Para tanto, em sua parte inicial, estabelece as bases político-jurídicas da transmissão destes bens à municipalidade, sistematiza a estrutura dos regimes de aquisição de coisas vagas, previstos pelo Código Civil, e estabelece o seu perfil funcional.

Ressalta-se, ao fim do estudo, a necessária atenção para a descoberta de bens móveis, os quais podem apresentar significativo valor, e questiona-se a noção de titularidade compulsória aplicada ao Município. A partir desta última construção afirma-se imprescindível a análise das vantagens oferecidas pela incorporação de certos bens ao patrimônio municipal.

\section{O MUNICÍPIO COMO DESTINATÁRIO DOS BENS VACANTES: POR UMA COMPREENSÃO POLÍTICO-JURÍDICA}

É conjuntura inegável a subsistência de visões do direito privado cuja a base consiste em reafirmar a técnica da subsunção, por meio da incidência da norma positivada ao mundo dos fatos. Porém, o rompimento com esta pretensa neutralidade é tarefa imprescindível, impedindo que as leis camuflem interesses não mencionados expressamente ou ocasionem o desinteresse acadêmico pelas razões que sustentam a permanência de determinados institutos (TEPEDINO, 2016, p. 22-31).

Nestes termos, a definição sistemática de passagem dos bens que não se encontram sob a titularidade de nenhum particular ao patrimônio público reflete-

\footnotetext{
10“Assim, considerando o abandono das coisas deixadas no imóvel objeto de locação, o locador deve ser liberado do encargo de depósito dos móveis restantes, podendo dar a destinação que melhor entender conveniente, a fim de desocupar o bem". TJDFT, AI no 0717665-26.2017.8.07.0000, Rel. Des. Carmelita Brasil, em 04.04.2018.

${ }^{11}$ Ressalte-se a esclarecedora retrospectiva e diagnóstico desta realidade atual dos bens presente em Teixeira (2017, p. 43-46).
} 
se em opção político-legislativa. Manifesta-se aqui, em uma economia capitalista, fundada na propriedade privada (art.170, inciso II, CR), a possibilidade expressa de que alguma das estruturas do Poder Público se aproprie de bens tipicamente privados que não estão sob o domínio de particulares.

Não se pode reputar inovadora esta possibilidade. Desde o Código Civil de 1916 a problemática dos bens sem dono, causada pelo abandono, renúncia ou herança sem herdeiro existente, resolveu-se pela sua passagem ao patrimônio de alguma das estruturas do Estado (arts. 589, incisos II e II e §2º ${ }^{\circ}$, art.606 e art.1.594) ${ }^{12}$.

Todavia, um rápido olhar sobre a legislação de outro país demonstra controvérsias sobre o tema, as quais reforçam a assertiva de que se constitui assumida escolha do direito brasileiro o referido tratamento. A título de exemplo, na Alemanha, em sede de direito sucessório, a ordem de vocação hereditária inclui colaterais até o grau infinito. Justifica-se este tratamento, segundo o ordenamento daquele país, por um receio de que qualquer passagem de propriedade ao Estado se torne em um passo para abolição da sucessão privada e de consequente admissão dos preceitos socialistas ${ }^{13}$.

A opção brasileira, como se vê, é diversa. Amparada no equilíbrio entre a garantia de propriedade privada (art. $5^{\circ}$, inciso XXII, CR) e o atendimento da função social (art.5o, inciso XXIII, CR), optou-se por transferir ao ente público bens e patrimônios vagos. Em um primeiro momento arrecadam-se os bens e, em processo judicial, procura-se o seu dono, seja ele o de coisa singularizada descoberta, ou abandonada, seja o titular do direito de aquisição causa mortis em heranças jacentes.

Superada esta fase, cujo objetivo será a manutenção do direito real de propriedade, o legislador fixa lapsos temporais após os quais não se transmitem, ou se perdem, os bens a particulares e incorporam-se ao patrimônio público. Esta normativa confere substância ao princípio da função social da propriedade no tema

\footnotetext{
12 San Tiago Dantas (1984, p. 164-165), também ao tratar da propriedade imobiliária, admite indiretamente esta importância da política legislativa ao definir o regime de titularidades proprietárias no direito brasileiro, de acordo ao sistema econômico vigente ("Na sociedade atual, especialmente na sociedade urbana (...) Os bens já se acham, normalmente, no patrimônio de alguém, ou no patrimônio do Estado ou no patrimônio dos particulares" (...). Especificando as razões disso, no momento em que escrevia, afirma: "No Brasil, até 1.850, teve-se a ocupação de imóveis embora o nosso direito positivo não desse normas bem claras ao instituto, que era regulado pelos princípios gerais do Direito Romano, mas o certo é que a lei $\mathrm{n}^{0}$ 601, de 18 de setembro de 1.850, seguida de um regulamento de 30 de janeiro de 1.854, veio encarar a situação de fato em que se encontrava a propriedade territorial, em grande parte ocupada pelos particulares que, por meio de uma apreensão das terras, se achavam colocados nelas como proprietários".

${ }^{13} \mathrm{O}$ relato encontra-se em Zimmermann (2018, p. 16).
} 
em estudo ${ }^{14}$, transferindo a titularidade do direito real a um novo proprietário, sem eleger um particular como adquirente ${ }^{15}$.

Pelo contrário, ao invés de conceder coisas e heranças vagas a pessoas sem qualquer relação anterior com estes bens, nomeia como seu titular determinado ente federativo, facilitando sua reversão ao interesse público geral. Trata-se não de ferramenta que serve para a defesa abstrata da propriedade privada como base do capitalismo, mas sim de possível contribuição material para a concretização dos Direitos Fundamentais Sociais, tarefa primordial do Estado.

Mudança significativa do Código Civil de 1916, empreendida pela Lei 8049/90 e mantida pela Codificação de 2002, foi a destinação dos bens vagos ao Município, e não mais ao Estado. Esta alteração enfatiza a ideia de concretização de interesses sociais.

Em comentário a esta sistemática, realizado no âmbito do Direito das Sucessões, Orlando Gomes (2015, p. 74) imputava a um jus imperii, ou seja, o domínio estatal sobre o território em que o bem se encontra, a razão para o estatuto legal. Ainda que seja possível identificar o sentido da afirmativa, reforçado pelo fato de que os imóveis abandonados e heranças vacantes arrecadam-se ao Distrito Federal ou ao Município (arts.1.276 e 1.844, Código Civil), a análise do argumento merece maior profundidade ${ }^{16}$.

Não se cuida meramente de conceder ao poder público a titularidade dos bens vagos no limite das circunscrições em que governa, mas sim de eleger como destinatário desta o ente federativo ${ }^{17}$ diretamente conectado a localidade. Neste

${ }^{14}$ Reconhecendo o fundamento da perda de propriedade por abandono na função social, Lustosa (2012, p. 13-15).

${ }^{15}$ Não é objeto específico deste trabalho a posse, por particulares, sobre os bens abandonados ou inseridos no patrimônio de herança vacante. Nas disposições sobre o abandono o próprio Código Civil reconhece o merecimento de tutela desta posse no art.1.276 ("O imóvel urbano que o proprietário abandonar, com a intenção de não mais o conservar em seu patrimônio, e que se não encontrar na posse de outrem, poderá ser arrecadado, como bem vago, e passar, três anos depois, à propriedade do Município ou à do Distrito Federal, se se achar nas respectivas circunscrições"). Quanto ao assunto, ver Lustosa (2012, p. 14-15).

16 Sublinhe-se que Gomes (2015, p. 75) admite não realizar comentário mais denso desta opção legislativa, ao reforçar que subsiste uma questão de fundamento político, mas importa ao direito privado a técnica de aquisição dos bens ("Distinguem os escritores o fundamento político do fundamento técnico-jurídico da sucessão do Estado. A ratio política está no jus imperi, mas o meio técnico de aquisição é proporcionado pelo direito privado, conquanto sirva a tutelar um interesse patrimonial que privado não é".

17 Embora se saiba da divisão de opiniões sobre a classificação do Município como ente federativo, o presente trabalho o classifica desta forma, interpretando a autonomia que a Constituição Federal de 1988 lhe concede, político, financeira e de funções próprias bem delimitadas. Para o resgate dos divergentes posicionamentos, e a defesa deste que ora se adota, assim como retrospectiva da posição dos municípios nas constituições anteriores, ver Dantas e Castro (2018, p. 93-96; 98-104). 
sentido, afirmou-se ser o Município uma espécie de comunidade de vizinhos institucionalizada, onde as políticas públicas direcionam-se a melhorar o cotidiano das pessoas habitantes daquele território (DANTAS; CASTRO, 2018, p. 107-109).

Desta maneira, o olhar unitário e atencioso sobre a mudança na codificação civil atual constata não uma destinação por poder sobre o território, e sim o objetivo de retorno das riquezas à comunidade próxima, de onde o ex-titular extraiu sua economia ${ }^{18}$.

Este fundamento atribuído à indicação legal de proprietários para adquirir as coisas vagas alinha-se, inclusive, a arrecadação de imóveis rurais pela União (art.1.276, §1). Se a está é constitucionalmente outorgado o dever de realizar a reforma agrária (art. 184, CR), é dever do Município a efetivação da política de desenvolvimento urbano (art.182, CR). No último caso, os bens vagos podem ser utilizados de diversas formas essenciais, a depender da conveniência administrativa, mas todas ligadas ao desenvolvimento da localidade, como a infraestrutura para serviços públicos e privados essenciais ou a instrumentalização do Direito Social à Moradia (MARRARA, 2018, p. 385).

\section{O REGIME DE AQUISIÇÃO DAS COISAS VAGAS: DIFERENTES ESTRUTURAS PARA MESMA FUNÇÃO?}

Considerando-se o estabelecimento da ratio, que legitima a entrega de bens e patrimônios vagos ao Município, será possível sistematizar as estruturas utilizadas pelo Código Civil para transmissão desta propriedade. Com lastro nesta análise torna-se possível entender a efetividade destas regras no cumprimento da função a que se destinam, qual seja, mediar a garantia de propriedade e sua função social. Em outros termos, ao mesmo tempo em que busca se evitar a expropriação da titularidade privada sem qualquer segurança, não se admite uma titularidade não preenchida por um longo tempo, ou de forma perpétua.

O Código Civil regula a matéria das coisas vagas, mais precisamente, as que outrora foram de um proprietário privado, nas disciplinas da descoberta, abandono, renúncia de imóveis e herança jacente. Exceto no caso de renúncia ${ }^{19}$ os procedimentos traçados para o reconhecimento de ausência de titularidade e transmissão ao Município são semelhantes, haja vista todos servirem a mesma função.

\footnotetext{
${ }_{18}$ No mesmo sentido, ver Pereira (2017, p. 186).

19 O tratamento especial justifica-se pelo fato de que na renúncia o abandono é declarado, registrando-se no Cartório de Imóveis o ato renunciativo, e perdendo-se a propriedade desde então (art.1.275, parágrafo único, CC). Caio Mário da Silva Pereira (2017, p. 221) afirma ser a renúncia a manifestação externa do abandono.
} 
Em regra, um fato ou ato jurídico indica a possibilidade de determinado bem ou patrimônio não se encontrar sob a titularidade de nenhum particular. Assim, arrecadam-se os bens e inaugura-se um procedimento judicial, o qual se desmembra em nomear um curador para manutenção do patrimônio e procurar o seu titular, ou uma pessoa apta a adquiri-lo ou, ainda, verificar a existência de abandono. Caso os titulares originais não reclamem o bem para si, e passado um determinado período de tempo, considera-se aquele desprovido de titularidade privada, ocorrendo sua incorporação ao patrimônio do Município.

Quanto à aquisição de bens móveis por meio da descoberta, o ato jurídico inicial é o achado de coisa perdida, da qual o descobridor se apossa. Perante esta situação, as normas do Código Civil obrigam o descobridor a procura do dono ou legítimo possuidor, para restituição da coisa ${ }^{20}(1.233$, caput e parágrafo único, CC).

No caso de a busca não alcançar seus objetivos, será aberto, perante o Poder Judiciário, o procedimento de coisas vagas, em que a coisa é depositada a coisa e são publicados editais, os quais instrumentalizam a tentativa de encontro dos proprietários pelas vias judiciais (art.746, CPC). Inexistindo quem prove condição de proprietário após o lapso temporal de sessenta dias o bem será vendido em hasta pública, pagando-se as despesas e recompensa ao descobridor, com transmissão do restante ao Município em que o objeto foi achado $(1.237, \mathrm{CC})$.

Quanto à perda da propriedade imóvel por abandono a previsão aparece em apenas um dispositivo da codificação, embora seja possível extrair daquele semelhante percurso. Deste modo, verificado o abandono, o qual se revela mediante atos jurídicos que indiquem a intenção, pelo proprietário, de não mais conservar o bem em seu patrimônio, o imóvel urbano poderá ser arrecadado como bem vago. Passados três anos o bem será incorporado ao patrimônio do Município ou Distrito Federal, a depender das circunscrições onde se encontra (art.1.276, Código Civil). Vale ressaltar a radical diminuição de prazo para este ato aquisitivo, o qual acontecia, segundo o Código Civil de 1.916, apenas dez anos depois da arrecadação como bem vago (art. 589 , $\$ 2^{\circ}$ ).

É no tocante a esta estrutura, que se destina a aquisição das coisas vagas imóveis, que se desenvolveu uma maior discussão doutrinária sobre o aspecto funcional do procedimento e sua coerência ao ordenamento jurídico. Motiva-se este destaque no lugar central, ao menos em longo período, atribuído à propriedade imobiliária no sistema capitalista. Neste contexto se instaura a divergência, em esforço de interpretação ao Código Civil, sobre o momento constitutivo da perda de propriedade, exteriorizada em três teorias distintas ${ }^{21}$.

\footnotetext{
${ }^{20}$ Entendendo que as normas do descobrimento apenas se aplicam aquele que se apossou da coisa, e que o descobridor poderá escolher fazê-lo ou não, Tepedino, Moraes e Barboza (2011, p. 512).

${ }^{21}$ Para um amplo debate sobre o tema, Lustosa (2012, p. 14-41).
} 
Em verdade, uma leitura conforme a axiologia constitucional demonstra visões que propõe a medida para o equilíbrio ou prevalência entre a garantia de propriedade e a função social. Nesta perspectiva, a teoria mais adequada será aquela da transmissão direta, a qual afirma imitir-se o Município na posse do imóvel a partir da arrecadação, perdendo o particular a titularidade do imóvel para o ente federativo, de forma definitiva, após o prazo trienal.

Por meio desta construção respeita-se a lei infraconstitucional e funcionalizamse seus ditames à satisfação, em mesma medida, de dois Direitos Fundamentais. $\mathrm{O}$ processo de aquisição da propriedade perdida, e os respectivos prazos materiais, exercem o papel de limites objetivos para caracterização de perda, a fim de que se realize seu uso em favor da função social. Caracterizam-se estes limites por sua condição de regras claras, suficientes a não descaracterizar a segurança jurídica que merece uma garantia constitucional.

Rejeita-se assim a leitura literal do art.1.275, inciso I, Código Civil, a qual propõe a teoria da perda imediata (que elege o abandono, por si só, como causa de perda da propriedade). Ocorre aqui desnecessária sobreposição do princípio da função social da propriedade, caracterizando-se o abandono de forma casuística e subjetiva (LUSTOSA, 2012, p. 23-26).

Em igual medida, a teoria da arrecadação (ou intermediária) demonstra-se inapropriada. Não obstante propor uma solução conciliativa, ao admitir a perda da propriedade no momento de arrecadação pelo Município, submetendo-se a incorporação definitiva a processo em que deve se manifestar o proprietário original, ignora-se o dispositivo legal. Ao invés de atribuir legitimidade ao lapso temporal positivado faz-se sua substituição, sem fundamento aparente, por um contraditório e ampla defesa (LUSTOSA, 2012, p. 23-26).

A transmissão do patrimônio vago em razão de morte segue o mesmo raciocínio das anteriores situações de coisas vagas. Aqui, o conhecimento do fato jurídico, não existência de herdeiros legítimos conhecidos, nem testamento, enseja a arrecadação judicial dos bens deixado, seja a pedido de terceiro interessado (como o Município), seja por ato de ofício do Juízo (art. 738, CPC). Constitui-se assim a herança jacente. Nomeia-se então um curador para a representação e manutenção da herança (art. 739, CPC) e publicam-se editais, que estarão dispostos em sítio eletrônico por três meses, ou, não havendo sítio, nos órgãos oficiais e imprensa por três vezes com intervalo de um mês entre cada uma delas (art. 741, CPC).

Um ano depois de publicado o primeiro edital, sem que haja habilitação de herdeiro, a herança passará da condição de jacência para a de vacância (art.1.820, CC; art. 743, CPC). Durante o lapso temporal de vacância apenas é permitido aos herdeiros necessários postular a herança na forma da ordem de vocação hereditária, mas não ao colateral (art.1.822, parágrafo único, CC). Demonstra-se 
aqui o privilégio a família afetiva e próxima, permitindo apenas aos herdeiros supostamente mais próximos do falecido, no quesito afeição, reclamar seus direitos hereditários.

Transcorrido o período de cinco anos da abertura da sucessão, momento de morte do falecido (GOMES, 2015, p. 77), os bens passarão ao domínio do Município, Distrito Federal, conforme a circunscrição que se encontra, ou a União, quando localizarem-se em território federal (art1. 1.822, caput, CC). A normativa traçada para vacância assemelha-se aquela da aquisição pela perda de propriedade até mesmo na exceção em que a herança é considerada imediatamente vacante, quando todos os chamados a suceder renunciarem ao patrimônio $(1.823, \mathrm{CC})$.

Apenas sublinha-se aqui o prazo distinto, e maior, do que o existente nas outras hipóteses já estudadas, como forma de conciliar a garantia fundamental de aquisição da herança, especificamente prevista na Constituição Federal (art.5,

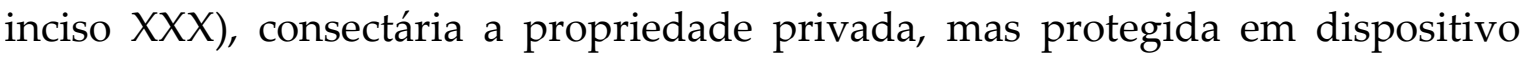
distinto, e a função social. No sentido deste aspecto funcional, não se considera o Município um herdeiro, o qual nem mesmo ocupa posição na ordem de vocação hereditária, atribuindo-se diferente razão e procedimento para transmissão de propriedade a este sucessor (ROSENVALD, 2018, p. 284).

Definido o esquema de estruturas para aquisição de coisas vagas, e, principalmente, sua função unitária, vislumbra-se a possibilidade de aplicarem-se dispositivos previstos originalmente para uma das situações a outra. O expediente busca suprir algumas insuficiências, cujos diferentes regramentos possuem em sua origem, de forma coerente ao ordenamento jurídico, vez que todos atendem aos mesmos objetivos.

Sob este prisma poderá suprir-se a falta de previsão de um procedimento para aquisição de bens imóveis abandonados pela utilização do procedimento de coisas vagas, positivado no Código de Processo Civil ${ }^{22}$. Assim como os editais buscam, primeiramente, encontrar o herdeiro ou proprietário que perdeu a coisa, a fim de mantê-la na titularidade de um particular, a ciência do abandonante também é necessária. Modifica-se apenas o conteúdo da informação: garantir a propriedade privada no caso de abandono não significa encontrar pessoa incerta, mas sim advertir que a perpetuação dos atos de não conservação no lapso trienal conduz a perda da propriedade.

Em outras palavras, o Poder Judiciário deixa claras as regras do jogo, conforme o sistema jurídico impõe, incitando ao particular para que atribua função social a sua propriedade, sob pena de perdê-la.

22 Parte da doutrina aceitava este posicionamento recorrendo a analogia, como demonstra Paulo Lustosa (2012, p. 27). 
Apenas em virtude da especificidade dos bens imóveis, o Juiz poderá usar das soluções flexíveis, admitidas nos procedimentos de jurisdição voluntária (art. 723, (PC), e citar especificamente o proprietário apontado na matrícula do imóvel. Contudo, harmonizando-se à regra processual de coisas vagas, o ato poderá ser direcionado pessoalmente e realizado uma só vez, sendo desnecessária a procura do proprietário na forma destinada aos processos contenciosos.

O procedimento também é maneira de neutralizar possível inconstitucionalidade da presunção absoluta de abandono quando a cessação dos atos de posse se soma ao não pagamento de ônus fiscais (art.1.276, §2, CC). Permitese ao proprietário, desta forma, assegurar sua titularidade, por meio do adimplemento dos débitos ou alegação de motivo relevante, como a insolvência civil, a qual o impede de realizar pagamentos ao fisco por obediência à ordem de preferências creditórias ${ }^{23}$.

Segundo o mesmo raciocínio, a distinção de lapsos temporais para aquisição de bens móveis (sessenta dias após a divulgação de edital ou notícia pela imprensa) e bens imóveis (três anos após sua arrecadação) é guiada por critério meramente estrutural. Na atual dinâmica dos bens não mais se pode reputar a razão desta diferença ao diminuto valor dos bens móveis, fato cuja expressividade econômica de ações de sociedade de capital aberto, quantias depositadas e bitcoins bem demonstram.

Portanto, a fim de assegurar-se a propriedade privada por tempo maior, de acordo com a relevância econômica do bem, a aplicação dos distintos prazos para incorporação ao Município (sessenta dias ou três anos) deve seguir o referido critério funcional. Ainda que os lapsos temporais sejam radicalmente diferentes entre si não se mostra exagerada a aplicação do prazo trienal aos bens móveis, pois podem exercer a mesma importância dos bens imóveis no atual cenário econômico.

Em último lugar, a possibilidade interpretativa poderá utilizar-se na decisão sobre o destino de imóveis que não apresentam grandes possibilidades de renda e nem do uso para concretizar a política urbana. Tendo em vista a necessária coerência entre o exercício dos poderes advindos da titularidade e as funções constitucionais outorgadas ao Município (MARRARA; FERRAZ, 2018, p. 93), reveste-se de potencialidade funcional a aplicação extensiva do art.1.237, parágrafo único, Código Civil.

De forma mais precisa, autoriza-se ao Município abandonar imóveis de diminuto valor aos que passem a possuí-los durante o período trienal de vacância,

\footnotetext{
${ }^{23} \mathrm{O}$ assunto da inconstitucionalidade do referido dispositivo não é tema central deste estudo, mas encontra-se amplamente discutido em outros trabalhos, como em Lustosa (2012, p. 40-56). Para a explicação e sugestão de um rol de preferências creditórias conforme a função de cada um dos créditos, ver Bucar (2017, p. 70-80).
} 
em caso de não exercício de posse direta sobre o bem pela municipalidade. $\mathrm{O}$ caso assemelha-se, no plano dos fatos, ao achado, pois o imóvel encontra-se vago, o processo de abandono pelo proprietário privado em curso e não se exige ao Município a averbação do procedimento para aquisição na matrícula do imóvel. Portanto, torna-se o conhecimento sobre a situação jurídica do imóvel dificultoso.

Mesmo que a configuração do diminuto valor ocorra de modo peculiar à situação do possuidor poderá ser merecedora de tutela. Imprescindível avaliar as possibilidades que traz o imóvel no sentido de construção de habitações populares, as quais podem servir a um grande número de famílias, e no desenvolvimento de infraestrutura na região. Contudo, pode se abandonar o bem, quando inexistente sua importância ao interesse público, em favor de um possuidor ou grupo de possuidores, privilegiando o direito fundamental à moradia.

Na unidade do ordenamento jurídico o dispositivo é coerente ao art.1.276, Código Civil em seu impedimento de arrecadação do imóvel quando houver posse de particular sobre aquele. Afinal, a arrecadação jurídica, sem o exercício dos direitos que a imissão na posse permite, revela contexto fático de abandono igual ao anterior, persistindo também a função da norma, valorizar a posse nestes casos. Do mesmo modo, esta manutenção de situações jurídicas da posse deve prevalecer no caso que esta se inicie no período de vacância hereditária, pelas mesmas razões desenvolvidas.

Por fim ressalte-se que o título a que o abandono do imóvel em favor do particular irá vigorar- uso, posse por tempo determinado, propriedade- caberá à discricionariedade administrativa no caso concreto.

\section{Advocacia Pública Municipal e a disciplina das coisas VAGAS: O PARADOXO DA AQUISIÇÃO BENÉFICA E AS TITULARIDADES COMPULSÓRIAS.}

Diante da destinação sistemática dos bens ao Município, e dos procedimentos judiciais que o direito impõe para a final aquisição destes bens, será essencial refletir sobre o papel institucional da Advocacia Pública Municipal ao tratar do tema. O exame do tema permite contribuições da técnica, e teoria jurídica, ao cotidiano forense deste ramo da Advocacia Pública Municipal.

Conforme os esquemas predispostos, a primeira tarefa do ente federativo interessado nos bens e patrimônios vagos será a de conhecê-los e arrecadá-los. Neste momento a advocacia para municipalidade exige um comportamento negocial, mais comum ao direito privado. Não se trata aqui de ressuscitar a divisão que antes se repudiou, mas sim reconhecer os rígidos limites a que a administração de bens públicos se submete. Porém, nesta fase inicial, a titularidade do ente federativo é apenas uma expectativa e a obrigação profissional de seus 
representantes só será alcançada ao agirem com as funções de mandatário ou gestor de negócios, na acepção popular do último termo ${ }^{24}$.

A licença para uma atuação mais afeita aos atos negociais dos particulares é, na realidade, a melhor maneira de resguardar o interesse público, e aqui se demonstra o paradoxo das aquisições benéficas. Uma análise abstrata, centrada unicamente no ato de adquirir um bem, e alienada do mundo econômico, sugere que toda aquisição significa entrada de ativos no patrimônio e, consequentemente, aumento de riquezas. No entanto, a dinâmica social indica outras consequências jurídicas envolvidas nesta questão.

Os patrimônios-e até os bens- poderão ser compostos por passivos que tornam suas aquisições em verdadeiros ônus ao novo proprietário. Por estas razões é essencial a atuação do advogado municipal na diligência de aquisição, semelhante àquela dos adquirentes privados, opinando, com o devido apoio técnico, sobre sua conveniência econômica.

Apenas por meio do levantamento de todas as informações sobre as coisas vagas o Município garante sua posição de transformar estes bens em utilidades aos seus administrados. Caso contrário o ente federativo assume posição indevida de agente econômico, destinando receitas ao pagamento de poucos particulares, sem que esta relação traga benefícios ao interesse público.

Conclui-se então que a arrecadação e posterior aquisição dos bens vagos exigem análise das vantagens econômicas e consequências jurídicas advindas de sua incorporação ao patrimônio municipal. Dito de outra forma, trata-se de avaliar quais entradas de coisas no patrimônio serão realmente úteis.

Questiona-se assim uma noção de titularidade compulsória (MARRARA, 2018, p. 390-391), a qual se formou, principalmente, no âmbito das heranças vacantes, restringindo o direito dos Municípios a renunciar herança, o que é permitido aos herdeiros (art.1.806, Código Civil). Diz-se também que na falta de proprietários caberá à municipalidade assumir esta posição por não admitir o direito brasileiro coisa sem titular (PEREIRA, 2017, p. 221). O assunto merece um melhor recorte sistêmico, analisada a axiologia que aqui se expôs.

Ao que toca as coisas vagas o único regramento expresso sobre constituir-se a destinação ao Município dever ou faculdade é o do art.1.276, Código Civil, onde afirma-se com clareza, que o imóvel poderá ser arrecadado e passar a titularidade

${ }^{24}$ Este adendo é importante vez que não se trata do instituto da gestão de negócios positivado no Código Civil, mais ligado aos atos unilaterais e ao próprio direito restitutório (arts. 861 a 875, Código Civil). Embora criticando a ineficiência da administração pública em administrar patrimônios privado, Baptista (2017, p. 259-262) admite que, nesta condição, o Estado assume papel semelhante ao de uma "imobiliária", ou seja, gestão e administração de bens, como qualquer outro particular. 
municipal. Não subsiste razão para que o raciocínio seja outro para as diversas hipóteses de coisas vagas, sobretudo quando a transmissão causa mortis ao Município ocorre em razão da renúncia pelos herdeiros, forma distinta de expressar o mesmo conteúdo do abandono.

Sob o prisma funcional, repita-se, a titularidade do Município apenas deve configurar-se quando benéfica ao patrimônio do ente federativo, e, consequentemente, à coletividade. Neste sentido, as previsões de direito sucessório oferecem importante resposta ao assunto, quando afirmam a possibilidade de credores aceitarem a herança em nome do herdeiro renunciante, com autorização do juiz, quando prejudicados pelo ato (art.1.813, Código Civil).

Da mesma forma, as hipóteses de abandono ou renúncia sobre as titularidades trazem à tona, como matéria de fundo, a possibilidade de rejeitar uma suposta riqueza pelos efeitos negativos desta no patrimônio do particular. A única diferença é no ato que revela esta função (na renúncia de herança a negativa de entrada no patrimônio e na perda de propriedade a deliberada saída), podendo haver a mesma abusividade.

O dispositivo carrega a potencialidade de permitir ao Município demonstrar desinteresse em figurar como adquirente do bem mas notificar os credores do extitular, resguardando os direitos destes. Nestes termos, os referidos poderão reclamar, em juízo, as coisas abandonadas para satisfação de seus créditos.

Eventuais questões, de patrimônio insuficiente ao pagamento de todos os credores e concurso instaurado sobre os bens, resolvem-se assim entre os particulares. Por meio deste procedimento concilia-se a faculdade de renúncia, que o Código Civil permite aos proprietários ${ }^{25}$, ou eventuais herdeiros, e a possibilidade de o Município evitar a titularidade destes bens vagos. Impede-se então uma titularidade compulsória, a qual se converte em uso das estruturas e recursos municipais para a movimentação dos interesses econômicos de poucos administrados, em prejuízo de toda a população.

O processo de análise das aquisições benéficas é de grande importância ao caso de abandono de imóveis. Um dos exemplos mais significantes de prática generalizada deste ato demonstrou-se na época da inflação alemã, quando muitos proprietários preferiram abandonar suas propriedades, pela falta de ativos cuja manutenção daquelas exigia (MONTEIRO, 2015, p. 222). Tal fato transpõe-se as crises cíclicas de mercado, momento em que poderá caracterizar-se uma disposição de imóveis por impossibilidade, ou inconveniência, de se pagarem os encargos pendentes sobre aqueles.

\footnotetext{
${ }^{25}$ Nos direitos reais estaria a possibilidade expressa nos arts.1.275 e 1.276, Código Civil, abandono pela renúncia ou atos informais. Afirmando existir a faculdade de renunciar os bens, inclusive para isentar-se de dívidas, prevista no Código Civil, ver Monteiro (2015, p. 219-220).
} 
Sob esta perspectiva o abandono visualiza-se, principalmente, quando compradores daqueles bens pretendem deles extrair uma garantia de renda, ampliação de investimentos e frustram-se em seus objetivos. Neste momento é necessária cautela redobrada do Município ao adquirir tais bens, que poderão acompanhar-se de um passivo formado de obrigações propter rem (tributárias, condominiais) pelas quais será responsável.

Embora se critique o conceito de titularidade compulsória não se descarta a função da advocacia municipal, no sentido de esforçar-se na construção de aquisições benéficas. A ressalva é importante pois as heranças vacantes são patrimônios sob os quais se pode atuar para transformação de sua aquisição em vantajosa. Diferente dos bens singulares abandonados sob os quais pesam encargos que se geram de forma contínua, os débitos e créditos que compõem o patrimônio após a morte costumam se estabilizar e responde o sucessor apenas até as forças da herança (ROSENVALD, 2018, p. 289).

Por tais razões, verificando-se a existência de passivo maior do que o ativo é dever do Município requerer a abertura do processo de insolvência, a aplicar-se ao patrimônio do falecido (para o qual se seguem as disposições do CPC 1973, segundo o artigo 1.052, CPC 2015). Mesmo não prevista sua legitimidade para tanto deve se interpretar extensivamente o art.753, Código de Processo Civil. Afinal, prevê o inciso III do dispositivo o pedido de insolvência pelo inventariante do espólio do devedor, sendo, no procedimento de vacância, o ente federativo quem assume posição muito semelhante de administração dos interesses do espólio.

\section{ENTRE OS INSTITUTOS DE DIREITO CIVIL E AS NOVAS REALIDADES DE AQUISIÇÃO DAS COISAS VAGAS: UM COTEJO URGENTE.}

Do mesmo modo que o referido raciocínio desperta posição crítica sobre o empenho de aquisição, pelo ente federativo, desconsiderando eventual atração de passivo, a realidade econômica também adverte para o não esquecimento de alguns bens. Ressalta-se aqui o necessário entendimento sistemático e funcional das estruturas aquisitivas, para que se evite sua negação a priori por considerá-la improvável ou destinada a coisas de pequeno valor. É o caso da descoberta.

Como anteriormente dito, o fato de o instituto aplicar-se as coisas móveis não significa sua relação com bens módicos, o que bem provam as grandes quantidades de dinheiro em espécie. Não apenas isto, por ser o Município o único destinatário destes bens em seu território, a situação coletiva de pequenos valores abandonados por múltiplos proprietários pode gerar uma expressiva quantia financeira.

Estas ocasiões são, inclusive, uma factível caracterização da descoberta nos tempos atuais. Fatores como a pulverização dos investimentos variados, de 
importâncias módicas, e a maior facilidade de acesso à justiça suscitam a possibilidade de constituírem-se créditos em favor de um determinado beneficiário, o qual não faz o devido levantamento destas quantias (em ações de consignação, por exemplo).

A descoberta será qualificada a partir do ato de quem atenta para esta situação, identifica os titulares, contabiliza estes valores e exterioriza estas informações. Classifica-se o bem como perdido por esta inércia de resgate pelo particular, exercício do direito de propriedade privada legitimamente esperado quanto ao que apresenta utilidade para o titular.

Neste sentido, a atuação da Advocacia Pública envolve o conhecimento do instituto da descoberta, participando o Município como sujeito ativo da procura destes bens e identificando quando o ato ocorreu. Para o cumprimento da função de descobridor o Município deverá oficiar a instituições financeiras, sociedades empresárias que detenham bens de terceiros, a fim de diagnosticar casos sobre os quais incide o instituto. Também por meio desta atuação garante-se o aproveitamento de todo o valor ao Município, pois não será necessário pagar a recompensa à terceiro caso o proprietário não procure a restituição destas coisas.

Todavia, será imprescindível, igualmente, alertar-se às descobertas ocorridas no plano fático e que não seguem o procedimento previsto pela lei federal. A problemática central que se instaura é a indevida detenção da coisa pelo descobridor, o qual apenas poderá exigir uma recompensa não inferior a cinco por cento do valor da coisa, mas arbitrada no caso concreto, além das despesas realizadas (art.1.237, CC). Caberá ao Município atuar em favor da obediência à legislação e assumir a posição que o ordenamento jurídico lhe atribuiu.

Instigante é o caso concreto dos depósitos judiciais abandonados, em que se verifica a tensão exposta. Cuidam-se de quantias depositadas em processos, a favor do credor, quando já declarada extinta a obrigação cumprida pelo devedor. Após o trânsito em julgado desta manifestação judicial, deve o credor tomar certas medidas, que o Código de Processo Civil de 2015 denominou de "satisfação do crédito".

Em outras palavras, esta satisfação de crédito nada mais é do que a entrega física do dinheiro ou adjudicação dos bens penhorados (art. 904, CPC). A partir do trânsito em julgado da declaração judicial de extinção da obrigação, o direito ao bem objeto do depósito integra o patrimônio de seu titular (credor) e, nesta hipótese, eventual inércia para levantá-lo indica a caracterização do instituto do abandono (derrelição), na medida em que seu titular se mantém despojado do corpus por força do não exercício do animus.

Ao perceber estas situações, a posição recente dos Tribunais, que tem sob sua jurisdição os processos que originaram estes depósitos, é de apropriação, pelo 
próprio órgão judicial, dos valores e destinação segundo a sua conveniência. Nestes termos foi a decisão proferida pelo Tribunal de Justiça do Rio de Janeiro nos autos do processo administrativo no 2008/259179, determinando a entrega do saldo das 114.365 contas de depósito judiciais administradas pelo Sistema de Gestão de Depósitos Judiciais do Banco Itaú S/A, cujo valor montava em $R \$ 68.960 .946,53$, ao FETJ (Fundo Especial do Tribunal de Justiça), conforme o Aviso TJERJ 73/201226.

Ignoram estes posicionamentos a aplicação da normativa da descoberta no caso de perda ou abandono de coisas móveis, constituindo-se, na vacância judicialmente declarada destes bens, o Tribunal de Justiça um descobridor. Assim, o dever deste é submeter os bens ao procedimento de coisas vagas (art. 746, CPC) e receber não a propriedade definitiva, a qual pertencerá ao Município, mas sim o valor da recompensa.

O supracitado aviso foi alvo de questionamento de legalidade no Conselho Nacional de Justiça, o qual afirmou a impossibilidade de conversão dos depósitos judiciais residuais em favor do Tribunal ${ }^{27}$.

Ressalte-se a forte carga política destas decisões, o que torna essencial a atenção para atos normativos incompetentes sobre o tema. A localização desta matéria será no Direito Civil, razão pela qual a competência legislativa para tratar do assunto será da União (art.22, inciso I, CR). Ou seja, a opção político-legislativa de razões, formas pela qual se perde a titularidade e o novo endereçamento desta compete ao referido ente federativo e não ao Estado ou Município.

Debate-se o assunto na Ação Direta de Inconstitucionalidade no 5975 , em trâmite no Supremo Tribunal Federal, contra a Lei 20.170/2018, do Estado de Goiás, a qual prevê que os recursos remanescentes de processos judiciais findos, arquivados ou não, e oriundos de depósitos não identificados, serão destinados ao fundo. Segundo a previsão normativa, a verba deve ser usada no custeio do regime próprio de previdência do estado, em seu equilíbrio atuarial. Neste caso discute-se a competência de lei estadual para determinar a titularidade de bens abandonados.

26 Aviso TJERJ 73/2012, disponível em http://www.tjrj.jus.br/documents/10136/1217804/13-062012.pdf.

${ }^{27}$ CNJ - PP - Pedido de Providências 0006026-24.2012.2.00.0000- Conselheiro Rel. DEBORAH CIOCCI - 181aㅗ Sessão Ordinária ${ }^{a}$ Sessão - j. 17/12/2013. Destaca-se da decisão os seguintes trechos: "Como já analisado por este Conselho, o depósito judicial possui vinculação ao objeto do processo de origem, razão pela qual o Poder Judiciário não pode, por simples ato de caráter meramente informativo (aviso), converter tais valores em recurso próprio, mesmo quando fundado em motivos nobres. Tais valores, mesmo que residuais ou abandonados pelas partes, constituem créditos específicos e particulares. Ademais, excepcionados os depósitos judiciais de natureza tributária, cuja possibilidade de criação de fundo único e sua utilização são matérias regulamentadas pela Lei $\mathrm{n}^{\mathrm{o}}$ 11429/2006, não existe permissivo legal que autorize a questionada conversão em receita pública." 
Enfim, pode se dizer necessária a atenção da Advocacia Municipal para identificar realidades de abandono. Aplica-se a elas a normativa em coerência ao ordenamento, e evitam-se estratégias políticas de alteração do destino previsto pela lei federal às coisas vagas.

\section{CONClUSÃO}

O presente trabalho objetivou apontar o ostracismo a que a disciplina das coisas vagas submeteu-se no desenvolvimento do direito privado e, a partir desta constatação, buscou desenvolver premissas para um debate inicial sobre o tema. Neste sentido, fixou-se a razão para a destinação sistemática dos bens vagos ao Município. A escolha político-legislativa pretende devolver as riquezas outrora acumuladas por um particular ao ente federativo responsável pela localidade onde o ex-proprietário desenvolveu suas economias.

Posteriormente, definiu-se a função para qual servem os procedimentos de aquisição da propriedade, qual seja, estabelecer uma via judicial de arrecadação dos bens conciliando-se a garantia de propriedade e sua função social. Desta forma, se estabelece um prazo para encontrar o dono da coisa (descoberta), eventual herdeiro de patrimônio vacante (herança vacante) ou declarar o abandono do imóvel, após o qual incorporam-se os bens ao ente federativo, permitindo seu aproveitamento.

Mesmo reconhecendo as diferenças estruturais entre os procedimentos sugeriu-se a aplicação unitária de alguns dispositivos em qualquer um deles, mesmo que previstos legalmente para um caso específico. Por meio desta interpretação pretende-se a efetividade na arrecadação e aquisição dos bens, visto que os desígnios de todas as suas diferentes formas devem atender a mesma racionalidade.

Assim soluciona-se a ausência de um processo específico em que se determine a ocorrência do abandono de imóveis e empresta-se um lapso temporal razoável a aquisição dos bens móveis de valor expressivo. Estabeleceu-se, igualmente, uma possibilidade de resolver conflitos possessórios entre o Município e particulares.

Enfim dedicou-se a parte final do estudo a estabelecer o papel da Advocacia Pública municipal na aquisição de bens, o qual muito se assemelha a de um mandatário que define quais aquisições devem ser feitas. Afastou-se, sob esta perspectiva, o conceito de titularidade compulsória e defendeu-se o repúdio a condição de adquirente que vincula o Município aos ônus que neutralizam os benefícios da incorporação de bens ao patrimônio ou trazem prejuízos.

Ainda se frisou a importância de atentar-se a aquisição de bens móveis de valor expressivo e o conhecimento de suas estruturas de aquisição. Como forma de 
exemplificar a importância desta questão utilizou-se como exemplo o caso dos depósitos judiciais abandonados.

A partir desta estrutura, e iniciais discussões, procurou-se aprofundar o debate sobre as coisas vagas e despertar o interesse para o tema. Mais do que isso, demonstrou-se a existência de sólidas bases político-jurídicas que embasam o sistema posto para aquisição dos bens vacantes e a relevância prática do assunto, especialmente no âmbito da Advocacia Pública.

\section{REFERÊNCIAS}

BAPTISTA, Patrícia. A funcionalização da propriedade pública: problemas da perspectiva civilista sobre o regime jurídico dos bens públicos. Revista da Faculdade de Direito da UERJ. Rio de Janeiro, n.31, p. 246-271, jun. 2017.

DANTAS, Ivo; CASTRO, Gina Gouveia Pires de. Os municípios e a federação brasileira: a importância desses no contexto constitucional brasileiro. In: NASCIMENTO, Carlos Valder do; DI PIETRO, Maria Sylvia Zanella; MENDES, Gilmar Ferreira (Coords.). Tratado de Direito Municipal. Belo Horizonte: Fórum, 2018.

DANTAS, San Tiago. Programa de Direito Civil III, Direito das Coisas, atualizado por Laerson Mauro. $3^{\prime \underline{ }}$ ed. Rio de Janeiro: Editora Rio, 1984.

GOMES, Orlando. Sucessões, atualizado por Mario Roberto Carvalho de Faria. $16^{\mathrm{a}}$ ed. Rio de Janeiro: Forense, 2015.

LUSTOSA, Paulo Franco. Abandono de bem imóvel no direito brasileiro. Monografia (pós-graduação em Direito Civil). Faculdade de Direito da Universidade do Estado do Rio de Janeiro. Rio de Janeiro, 2012.

MARRARA, Thiago. Bens Municipais: espécies, aquisição, regimes, uso e cobranças. In: NASCIMENTO, Carlos Valder do; DI PIETRO, Maria Sylvia Zanella; MENDES, Gilmar Ferreira (Coords.). Tratado de Direito Municipal. Belo Horizonte: Fórum, p. 385-416,2018.

MARRARA, Thiago; FERRAZ, Luciano. Tratado de Direito Administrativo Volume III- direito administrativo dos bens e restrições estatais à propriedade. In: DI PIETRO; Maria Sylvia Zanella (org.). Tratado de Direito Municipal. Belo Horizonte: Fórum 2018. 
MONTEIRO, Washington de Barros. Curso de direito civil, volume 3, direito das coisas, atualizado por Carlos Alberto Dabus Maluf. 44aㅡ ed. São Paulo: Saraiva, 2015.

MORAES, Maria Celina Bodin de. A caminho de um direito civil-constitucional. Direito, Estado e Sociedade. Rio de Janeiro, volume 1, p. 59-73, 1991.

MORAES, Maria Celina Bodin de. A nova família de novo- estruturas e função das famílias contemporâneas. Revista Pensar. Fortaleza, v.18, n.2, mai/ago, p. 587-628, 2013.

PEREIRA, Caio Mário da Silva. Instituições de direito civil, volume I, introdução ao direito civil, teoria geral do direito civil, atualizado por Maria Celina Bodin de Moraes. Rio de Janeiro: Editora Forense, 2010.

PEREIRA, Caio Mário da Silva. Instituições de direito civil, volume IV, direito das coisas, atualizado por Carlos Edison do Rêgo Monteiro Filho.25. ed. Rio de Janeiro: Forense, 2017.

PEREIRA, Caio Mário da Silva. Instituições de direito civil, volume VI, direito das sucessões, atualizado por Carlos Roberto Barbosa Moreira. 24 ${ }^{\mathrm{a}}$ ed. Rio de Janeiro: Forense, 2017.

ROSENVALD, Nelson; FARIAS Cristiano Chaves de. Curso de direito civil: direito das sucessões. $4^{\underline{a}}$ ed. Salvador: Ed. Jus Podvim, 2018.

ROSENVALD, Nelson. Curso de direito civil: direitos reais. $4^{\underline{a}}$ ed. Salvador: Editora Jus Podvm, 2018.

TEIXEIRA, Danielle Chaves. Planejamento sucessório: pressupostos e limites. $1^{\underline{a}}$ reimpressão. Belo Horizonte: Fórum, 2017.

TEPEDINO, Gustavo. Premissas Metodológicas para a Constitucionalizado. Revista de Direito do Estado. Ano 1, no 2abril/junho, p. 37-53, 2007.

TEPEDINO, Gustavo. O papel atual da doutrina do direito civil entre o sujeito e a pessoa. In: TEPEDINO, Gustavo, TEIXEIRA, Ana Carolina Brochado, Almeida, Vitor (Coords). O Direito Civil entre o sujeito e a pessoa: estudos em homenagem ao professor Stefano Rodotà. 1aㅡ ed. Belo Horizonte: Fórum, p. 17-35, 2016. 
TEPEDINO, Gustavo; MORAES, Maria Celina Bodin de, BARBOZA, Heloísa Helena. Código Civil interpretado conforme a Constituição da República, volume III. Rio de Janeiro: Renovar, 2011.

ZIMMERMANN, Reinhard. Does the Law of Sucession Reflect Cultural Differences? Nova Zelândia: Eleven International Publishing, 2018. 